\title{
Improved Engagement of Undergraduate Students in a Third Year Chemistry Lecture
}

\author{
Pavla Simerska ${ }^{1,2}$ \\ ${ }^{i}$ School of Chemistry and Molecular Biosciences, The University of Queensland; \\ ${ }^{2}$ Office of Medical Education, Faculty of Medicine, The University of Queensland \\ Corresponding author.Email: p.simerska@uq.edu.au
}

\begin{abstract}
Student engagement in traditional chemistry lectures has been challenging. In this study, student engagement in and outside of the classroom was enhanced by student pre-class preparation and interactive lectures including group and class discussions, quizzes, short videos and problem-solving activities. The participation and perception findings obtained from this intervention confirm that students can be engaged during the undergraduate chemistry lectures. Students also reported to prefer and enjoy this form of active learning instead of the traditional lecture format. The majority of students reported they used a deep approach for their learning, understood the lecture content more and felt better prepared for their examination. Interestingly, students, even though feeling intellectually challenged, were asking for more reading materials, quizzes, discussions and problem-solving tasks.
\end{abstract}

Keywords: Lecture, Student Engagement, Chemistry.

\section{INTRODUCTION}

Students usually forget the majority of memorized information by their graduation [1, 2]. Therefore, our focus should be on teaching skills to find, understand, evaluate and apply scientific knowledge. It is important to know who our students are, what knowledge they have and what their needs for future professions are [3, 4]. Only then we can design our courses in a way that helps students to learn a subject effectively. One of the definitions for understanding was described in the literature as "Understanding is the residue of thinking" [2]. If we support students to think about chemistry and its principles in an active way [2, 3] they might understand it better and be able to apply it in their future.

Pundak and Rozner [5] reported that new teaching strategies, such as the portfolio-based approach, can increase students' active deep learning and understanding of a topic. However, implementing these strategies to a science course can be challenging [5, 6]. Yew [7] demonstrated that science students often use a surface approach to learning, which might be due to the fact that a large amount of information is generally required to be memorized, especially in chemistry. Assessment can also encourage memorization without requiring deeper thinking or understanding [8]. To avoid this, the teaching and assessment strategy presented herein included interactive activities promoting deep learning.

Students generally tend to lose attention after 10-30 minutes of passive listening, their concentration drops down and deep learning is not facilitated [2, 9]. Short activities during a lecture were found to keep students "awake" [7]. A standard lecture format can cause vigilance decrement but this effect was not confirmed when a presented topic was popular for students [9].

Elliot [10] reported that a small-numbered class and a lecture time from mid-morning to early afternoon had the highest percentage of students responding to the lecturer's questions. The question-asking approach used in different ways was reported to actively engage students in a class [3]. Charlton [11] suggested not providing lecture handouts as it is encouraging students to passively listen. In contrast, Domizio [4] recommended giving handouts; saying that students will not have to write down everything and will listen more calmly. A compromise method where there is a missing text in the handouts [10] might be an effective way of encouraging students to pay attention and learn more 
from lectures and hopefully understand more the lecture content.

The use of group assignments, in-class discussions, demonstrations, peer-teaching, problem-solving tasks and flipped learning approaches proved that students were more active, using a deep approach to learning and their measurable learning outcomes were higher than those taught in a traditional format $[2,4,5,7,9,12]$. Using laptops during classes and website and/or podcast learning methods were studied extensively $[13,14,15]$. Medical students using e-learning methods had a better understanding of the topic than those being taught traditionally [14]. Information and communication technology (especially video clips and online tests) was also recommended $[15,16]$.

\section{METHODOLOGY}

Quantitative educational research approaches were used in this study to answer the research question: "Can undergraduate students engage in a third year chemistry lecture?". Quasi-experimental and survey research designs were applied to determine the effect of the intervention.

This study focused on a third year undergraduate medicinal chemistry course with an enrollment of around 40-50 students. Students were observed to be assessment/exam-oriented, applying a surface approach to their learning and memorizing the content without understanding it. The course was based on lectures with three contact hours per week divided into two lecture slots.

The assessment consisted of two marked assignments and a final exam. Students' main focus was on the final examination, and thus they were not engaged during the lectures and were using mainly surface approach and memorization for their learning. This was most likely because exam weighting was $60 \%$ and required learning of a large amount of content without any feedback on the students understanding of the topics during the semester. The understanding of the reaction mechanisms and the chemistry principles is crucial for students to comprehend to have the ability to apply them in future projects. It was important to actively engage students during lectures and encourage them to use a deep approach to learning, which should lead to their understanding of the topics [17].

To address the educational question: "Can undergraduate students engage in a third year chemistry lecture?", learning activities in the classroom and the final examination were changed to ensure a constructive alignment [18].

\subsection{Modifications of lectures/learning activities}

To engage students during a lecture [2] and to make the subject more popular [9], classroom/online discussions were introduced. More examples of diseases and their treatments were discussed during lectures to enhance the connection and importance of medicinal chemistry in real life. Students were also asked to name the reasons why they had decided to study medicinal chemistry.

New interactive activities promoting deep learning including frequent quizzes testing students' deep learning, understanding and critical thinking in medicinal chemistry, were discussed inside/outside of class and rewarded by bonus points. Students were provided recommended readings and quizzes in advance to prepare for the class during which discussions were initiated.

To increase students' attention and active engagement [3], lectures were divided into 3-4 sections separated by breaks when students were asked to write/answer relevant questions individually, in pairs or groups (4-5 students). The lecture slides and handouts were missing some parts, usually the activity - questions, short videos etc. [10,19] to ensure students actively listened and paid attention during the lectures.

\subsection{Modification of exam assessment}

Exam questions aimed to test mainly students understanding not memorization; students were explained the importance of understanding the topics and the style of examination; they were provided with quizzes before lectures to solve and discuss in classes. This frequent feedback is expected to help students to critically think and understand the lecture material, be better prepared for the examination lowering thus their stress, and avoiding surface learning. Students were rewarded with bonus marks if they opted to submit their quizzes before the group class discussions and if the answers were correct. Both, quizzes and the final examination were based on multiple-choice and openended questions [8].

One of the reasons why students apply the surface approach to learning is a large amount of information required to be memorized/assessed [20]. Another reason could be the fact that students did not receive helpful feedback on their learning. This might be not only demotivating, but students might not realize they do not understand certain topics. Earlier, frequent, class and individual feedback was provided to students within this intervention.

\subsection{Data Collection}

The inclusion of summative and formative evaluation, as well as participation and perception, were used for valid and meaningful conclusions [21, 22, 23]. "Evaluation is a continuous and continuing process" [20]. Hence, the evaluation was performed before, during and after the intervention. To evaluate the change in the lecture style and its effect on the student engagement in 
the classroom, the evaluations were carried out using multiple sources of evidence, different data collection and analysis to allow triangulation and more significant result interpretation [20, 24].

Perception data were collected from the student survey, which was given to students at the end of the intervention, and the Student Evaluation of Course and Teacher (SECaT). As a part of the anonymous survey, students were asked to answer eight Likert scale questions and two open-ended questions about the intervention and its impact on their engagement and learning as well as future improvement. The Likert scale response was designed for easier and more precise data interpretation [25]. SECaT is on the other hand a formal way of receiving feedback from students about the whole course and an individual teacher. Perception about student engagement by three lecturers was monitored throughout this study.

The project performance data comprised of student participation/engagement in a "motivation statement", in/out of class participation, and participation and marks obtained from the quizzes. The quantitative data were analysed to provide an understanding of the effect of the interactive lectures on student engagement in class. The "motivation statement" activity was included as a positive control. For this purpose, it was a simple activity, which did not require student learning, but only participation in answering a question: "Why did you choose to study medicinal chemistry?"

Qualitative data from students' comments, survey, and lecturers' comments enriched all the above quantitative data and helped to identify themes reoccurring [26]. The formative evaluation (qualitative data) was performed before, during and at the end of this study. The summative evaluation was done at the end of the study and was based on the student survey, performance at quizzes, and SECaTs; all compared to those of the previous year.

\subsection{Ethical Issues}

Out of many ethical issues in teaching [27], there were some associated with the application of this innovation, which had to be addressed. Students who could not attend the lecture/intervention could be disadvantaged. Therefore, the quizzes and handouts were provided online and their submission was accepted in person or via email. Some content was not discussed in class in order to gain some time for interactive class activities but additional reading material/notes were provided. All students were encouraged to participate in group activities, quizzes and discussions, to not be disadvantaged in case only a sample group for this study was selected. Every student had a chance to participate and, if successful, be rewarded with bonus marks. Students were assured their responses in the survey would not impact their course grade as the completion of the student survey was voluntary and anonymous [28] to avoid the fear of non-participation. Ethical clearance for this study was obtained from the University of Queensland (No. 12-045).

\subsection{Data Analysis}

Open-ended questions from the student survey and comments from participants of this study were analysed by thematic analysis $[29,30]$. Standard statistical analysis methods were used to further clarify the importance of collected data [31, 32]. Likert scale survey responses were converted into numerical scores, interpreted and, where possible, analysed by 1 way ANOVA analysis $(\mathrm{P}<0.05)$. The results from the student feedback on a course and teaching quality (SECaTs) were compared to those from the previous year and statistical significance was confirmed by an unpaired t-test (two-tailed $\mathrm{P}$ value, $\mathrm{P}<0.05)$. This triangulation combining the results of qualitative and quantitative studies from different sources provided more knowledge than separate analysis [33].

\section{RESULTS}

\subsection{Student survey Likert scale questions (Perception data)}

Student responses to the survey Likert scale questions are displayed below in Figure 1. Some questions were designed to be negative to ensure students were reading the questions and not only selecting one scale. They were developed to notice any inconsistency in individual student responses. 
Q1. I have actively participated and/or been engaged in the classes (e.g. filling quiz, group discussion).

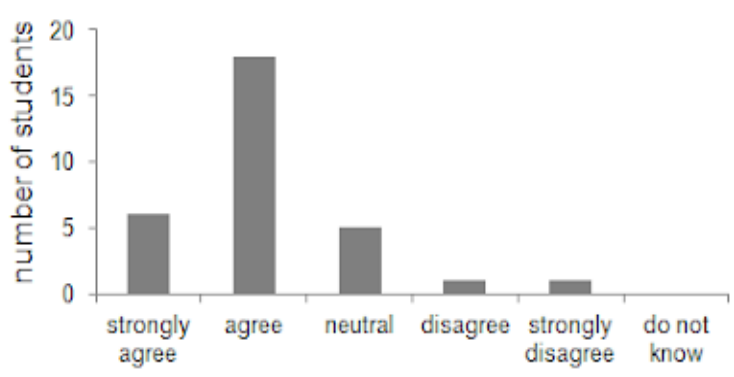

Q3. I have learnt what I expected to learn.

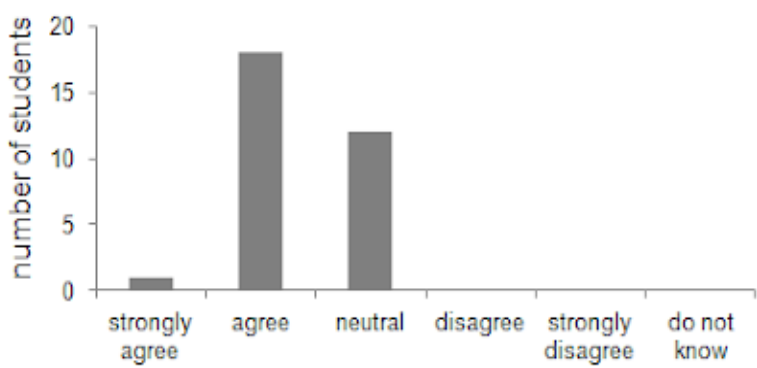

Figure 1 Student survey responses to Likert scale question about the intervention.

Q5. This module was intellectually challenging for me.

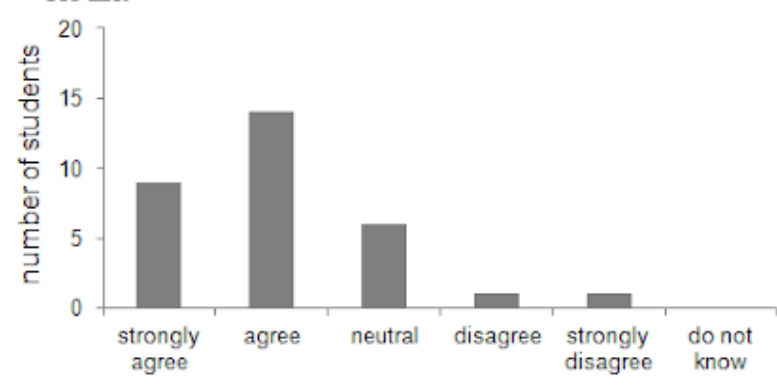

Q7. I did use deep approach to my learning, not just memorisation.

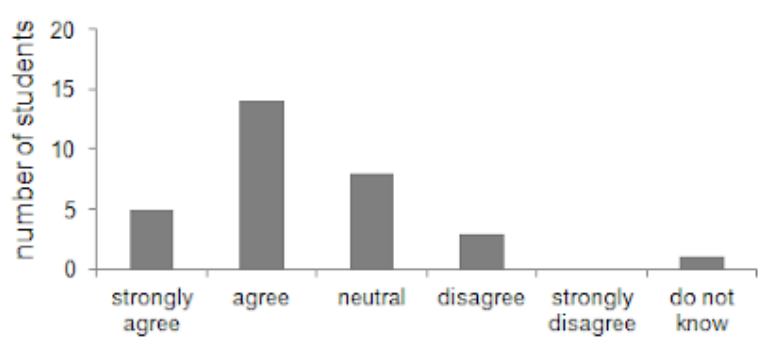

To evaluate this intervention, the Likert questions were coded (1-5 scale), negative statements reverse coded, and percentages of student responses with an average response calculated (Table 1). The majority (Q1: $78 \%$ ) of the students agreed that they actively participated and/or been engaged in class, with only 2 students disagreeing. A similar result (Q2: 71\%) was
Q2. I do not understand and cannot apply the content of the lectures

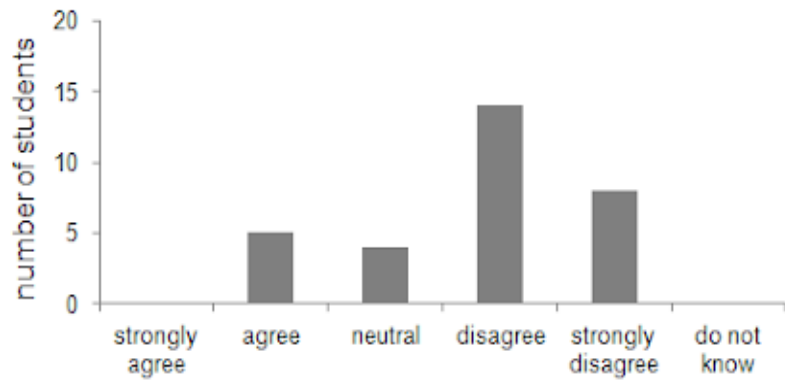

Q4. This teaching method was less efficient for my learning than “traditional lecture without activities".

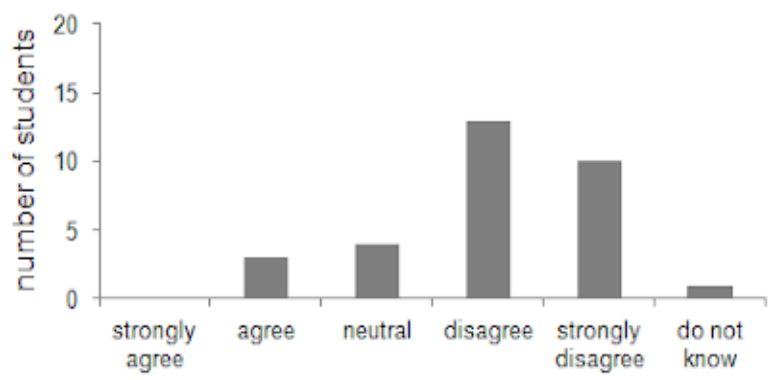

Q6. I did not enjoy the class with active interactions more than I would the traditional lecture setting.

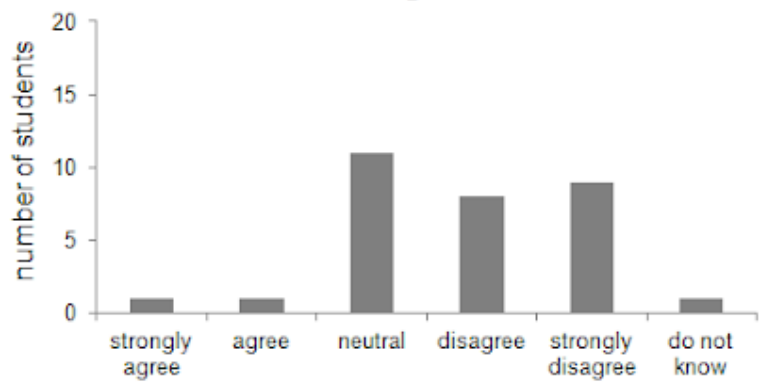

Q8. I do not feel prepared for the exam more than I would if did not participate in/outside the class activities (quizzes, discussions).

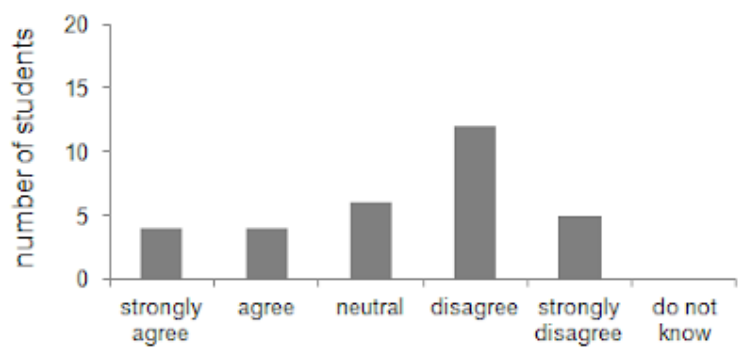

obtained about student understanding of the lecture content. Even though the majority (Q3: 61\%) agreed that they learned what they expected, surprisingly, 39\% of students chose a neutral response. The interactive lecture was perceived by students as a more efficient (Q4: 77\%), intellectually challenging (Q5: 74\%) and still enjoyable (Q6: 57\%) or neutral (Q6: 37\%) method of learning. The 
majority (64\%) of students used, according to their perception, a deep approach to their learning and $89 \%$ of those (55\% total) reported feeling better prepared for the examination with average scores ranged from $3.3(\mathrm{Q} 8)$ to 4 out of 5 .

Overall, $66 \%$ of students evaluated this project as positive (Figure 2), and less than $15 \%$ disagreed. All data were statistically different by 1-way ANOVA analysis $(\mathrm{P}<0.0001$, means $\mathrm{P}<0.05)$.

\subsection{Student survey open-ended questions (Perception data)}

Responses to student open-ended survey questions analysed by thematic analysis are summarized in Table 2. $45 \%$ of respondents would like to receive additional readings, tutorials and/or workshops or longer interactive sessions ("a whole allocated time each week for working through problems").

Table 1. Student survey responses to Likert scale questions (1-5 scale).

\begin{tabular}{|l|c|c|c|c|c|c|}
\hline & $\begin{array}{c}\text { Strongly } \\
\mathbf{a g r e e} \\
(\boldsymbol{\%})\end{array}$ & $\begin{array}{c}\text { Agree } \\
\mathbf{( \% )}\end{array}$ & $\begin{array}{c}\text { Neutral } \\
(\boldsymbol{\%})\end{array}$ & $\begin{array}{c}\text { Disagree } \\
(\boldsymbol{\%})\end{array}$ & $\begin{array}{c}\text { Strongly } \\
\text { disagree } \\
(\boldsymbol{\%})\end{array}$ & $\begin{array}{c}\text { Average } \\
(\mathbf{o u t} \text { of 5) }\end{array}$ \\
\hline $\begin{array}{l}\text { Q1. I have actively participated and/or been } \\
\text { engaged... }\end{array}$ & 20 & 58 & 16 & 3 & 3 & 3.9 \\
\hline Q2 I do understand and can apply the content... & 26 & 45 & 13 & 16 & 0 & 3.8 \\
\hline Q3 I have learned what I expected... & 3 & 58 & 39 & 0 & 0 & 3.6 \\
\hline Q4 This teaching method was more efficient... & 33 & 44 & 13 & 10 & 0 & 4.0 \\
\hline Q5 This module was intellectually challenging $\ldots$ & 29 & 45 & 20 & 3 & 3 & 3.9 \\
\hline Q6 I did enjoy the class with active interactions... & 30 & 27 & 37 & 3 & 3 & 3.8 \\
\hline Q7. I did use deep approach to my learning.... & 17 & 47 & 26 & 10 & 0 & 3.7 \\
\hline Q8 I do feel prepared for the exam $\ldots$ & 16 & 39 & 19 & 13 & 13 & 3.3 \\
\hline
\end{tabular}

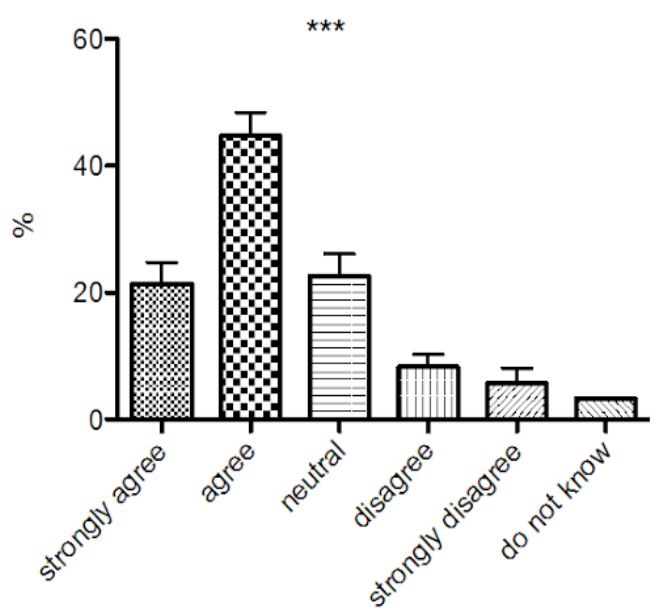

Figure 2 Overall student perception about the intervention. Response Likert scale data were coded, negative statements were reverse coded and statistically evaluated (***; 1-way ANOVA analysis, $\mathrm{P}<0.0001$; means significantly different $\mathrm{P}<0.05)$.

A response about the lecture slides was a second common topic (29\% responses). The third common suggestion for improvement was about quiz questions (23\%). Regarding suggestions for improvement of learning and understanding (Table 2), similar ideas came up, $42 \%$ of students recommending more questions/quizzes, discussions and problem-solving activities. 


\subsection{SECaTs data (Perception data)}

Raw data obtained from the questions on SECaTs were compared to those of the previous year. It was revealed that 7 (scores) or 5 (agreement) out of 8 questions about the course improved (33 respondents) when compared to the previous year (28 respondents). The biggest improvement (scores 3.46 to $4.24,16 \%$ increase or agreements $47 \%$ to $79 \%, 32 \%$ increase) was noticed in response to CQ6 (I received helpful feedback). This increase was significant $(* *)$ as confirmed by unpaired t-test (two-tailed $\mathrm{P}$ value $0.0021, \mathrm{P}<0.05$; $\mathrm{t}=3.250 ; \mathrm{df}=50)$.
Students perceived improvement in the course as well as in the teaching evaluation. The majority ( 5 out of 8 ) of the ratings improved $(2-16 \%), 2$ remained the same and 1 was slightly lower (4\%). The biggest and significant (***, unpaired t-test, two-tailed $\mathrm{P}$ value $0.0001, \mathrm{P}<0.05$; $\mathrm{t}=4.160 ; \mathrm{df}=57)$ improvement $(3.93$ to $4.72 ; 16 \%$ increase) was noticed in the response to TQ6 (Encouraged student input). Observing the number of students agreeing with the statements, an impressive $100 \%$ agreement stands out to TQ6 (22\% improvement).

Table 2. Student responses to open-ended questions in the survey.

\begin{tabular}{|c|c|}
\hline Q9: What would you improve in this interactive lecture module? & $\begin{array}{l}\text { No. of } \\
\text { responses (\%) }\end{array}$ \\
\hline $\begin{array}{l}\text { Additional reading, tutorials, workshops } \\
\text { "it would be better if the time of interaction session becomes longer" } \\
\text { "definitely quizzes like this for each module" } \\
\text { "make quizzes/discussions worth 5-7\% of course" } \\
\text { "more outside reading sources provided to further my knowledge" } \\
\text { "allocated time each week for working through the problems" }\end{array}$ & 45 \\
\hline $\begin{array}{l}\text { Lecture slides } \\
\text { "some slides didn't make sense until I came to the lecture and they were explained" } \\
\text { "it was almost impossible to find quiz answers from reading the slides before the lecture" }\end{array}$ & 29 \\
\hline $\begin{array}{l}\text { Quiz questions } \\
\text { "clearer questions that are easier to understand before lectures" } \\
\text { "had to search for answers" } \\
\text { "more questions" } \\
\text { "more feedback with model answers" }\end{array}$ & 23 \\
\hline Q10: What would help you to learn more and understand the principles in medicinal chemistry? & $\begin{array}{l}\text { No. of } \\
\text { responses }(\%)\end{array}$ \\
\hline $\begin{array}{l}\text { More questions/quizzes, discussion, problem solving } \\
\text { "if we had a problem solving session each week" } \\
\text { "perhaps have a workshop to do questions with the class" } \\
\text { "more practice problems through outside of classroom sessions", } \\
\text { "problems sheets with worked solutions" }\end{array}$ & 42 \\
\hline
\end{tabular}

\subsection{Lecturers' interviews (Perception data)}

Lecturers' perceptions of students' engagement in the lectures are summarized in Table 3. 
Table 3. Lecturers' perception of students' engagement.

\begin{tabular}{|l|c|c|c|}
\hline & $\begin{array}{c}\text { Lecturer } \\
\mathbf{\# 1}\end{array}$ & $\begin{array}{c}\text { Lecturer } \\
\mathbf{\# 2}\end{array}$ & $\begin{array}{c}\text { Lecturer } \\
\mathbf{\# 3 *}\end{array}$ \\
\hline $\begin{array}{l}\text { Interactivity (1-5 } \\
\text { scale with 5 highest) }\end{array}$ & 1 & 3 & 4 \\
\hline $\begin{array}{l}\text { Students answering } \\
\text { lecturer's questions } \\
\text { during lecture }\end{array}$ & - & A few & $10-15$ \\
\hline $\begin{array}{l}\text { Students asking } \\
\text { lecturer questions }\end{array}$ & 0 & $3-4$ & $8-14$ \\
\hline $\begin{array}{l}\text { Students contacting } \\
\text { via email, } \\
\text { discussion board }\end{array}$ & 0 & 3 & $80+66$ \\
\hline
\end{tabular}

*Lecturer 3 included the intervention in their lectures.

\subsection{Student informal discussions and comments (Perception data)}

When students were supported to engage in-class discussion, they were more engaging and interacting with the lecturer too. Informal feedback received from students during discussions after the lectures with the intervention:

$$
\text { "we like the classes" }
$$

"we like the activities, discussions, quizzes"

"it is great because it is fun and not a boring lecture"

"we already feel we are learning so much"

"we like the quizzes because we can practice"

\subsection{Reflective journal (Perception data)}

The observations during and after the interactive lectures supported the findings discussed above. Generally, students participated in the class activities (write and/or answer questions individually and/or in groups) and discussions. Short video clips were found to be also very effective starting points for discussions.

\subsection{Student engagement/participation (Performance data)}

Figure 3 shows that $71 \%$ of students participated in the motivation statement activity, the same number of students were present during the lecture when the interactive activity was explained.

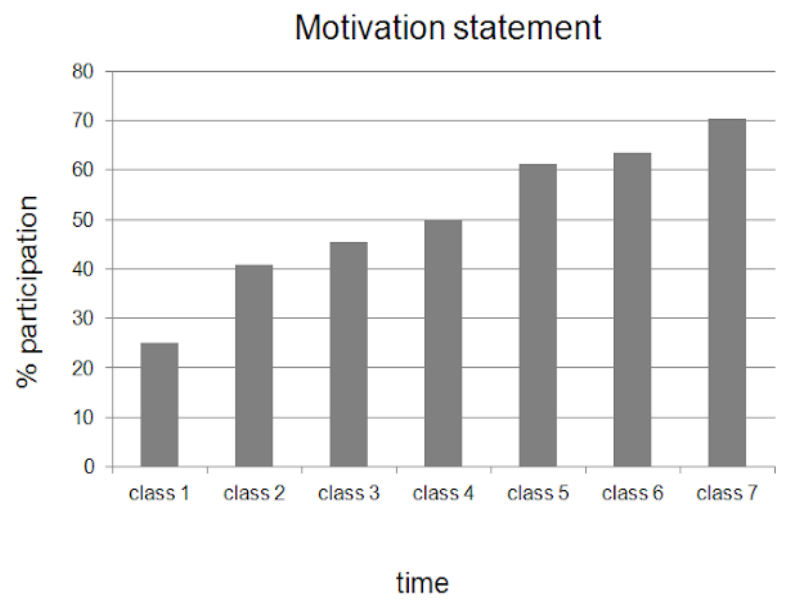

Figure 3 Total participation of students in non-marked activity (motivation statement).

Students were explained that their engagement and participation in classes will support their learning. Thus the engagement in this simple, not knowledge testing, non-marked activity grew from $25 \%$ to $71 \%$. The maximum participation of students in the marked (bonus marks) activity (quizzes) was also $71 \%$ (Figure 4 ). The majority $(84 \%)$ of students participated in one of the quizzes at least once (some students emailed the quiz to get a bonus mark and did not attend the lecture). The final student survey was given to students in class and again the participation was $71 \%$. Therefore, this value was estimated to be a $100 \%$ response of attending students.

The average participation in quizzes was in total $58 \%$ or $82 \%$ of lecture attending students (when $71 \%$ was taken as $100 \%$ ). 

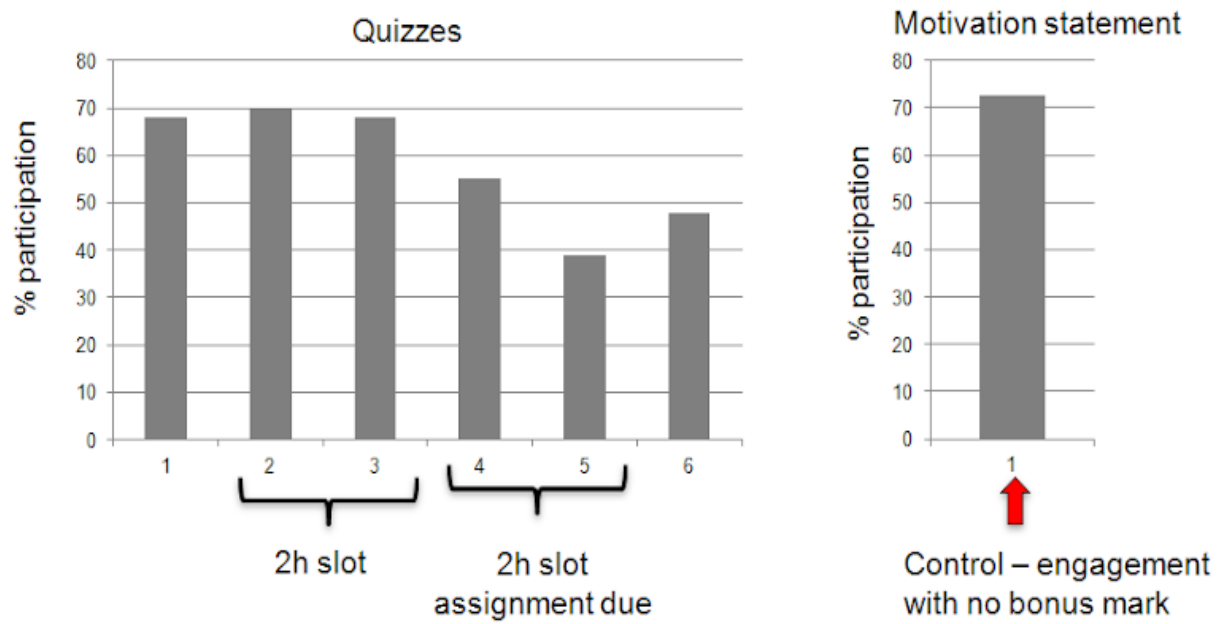

Figure 4 Student (total number) participation at quiz submission with the positive control (motivation statement).

\subsection{Quiz marks (Performance data)}

Results show (Table 4, average marks) that students can learn almost $50 \%$ of the lecture content without attending the lecture.

\section{DISCUSSION}

The majority of students agreed that they actively participated/been engaged in class and understood the lecture content. Even though the majority agreed that they learned what they expected, surprisingly, over onethird of students chose a neutral response. Unfortunately, it is not clear if they expected to learn something different or if they simply did not know what they wanted to learn. The majority of students reported the interactive lecture to be more efficient (Q4: "This teaching method was more efficient for my learning than traditional lecture without activities"), intellectually challenging and still enjoyable method of learning, they used a deep approach to their learning and felt better prepared for the examination. There was some inconsistency in some of the student responses to Question 8 when compared to their responses to other questions. Even though it was apparent that those students made a mistake (perhaps due to a limited time) in $\mathrm{Q} 8$, those responses were not discarded.

Overall, the majority of students evaluated this project as positive, and less than $15 \%$ of students disagreeing (note this would be lower if the incorrect responses for Q8 were excluded). Based on the student perception results shown in Figure 1, 2 and Table 1, this intervention was successful.

Table 4. Student participation in voluntary quiz submission before each lecture with average marks.

\begin{tabular}{|l|c|c|c|}
\hline & Total response (\%) & $\begin{array}{c}\text { Response of students in class } \\
(\%)\end{array}$ & $\begin{array}{c}\text { Average mark } \\
(\%)\end{array}$ \\
\hline Quiz 1 & 68 & 97 & 73 \\
\hline Quiz 2 (2h slot) & 71 & 100 & 67 \\
\hline Quiz 3(2h slot) & 68 & 97 & 41 \\
\hline $\begin{array}{l}\text { Quiz 4 (2h slot, } \\
\text { assignment due) }\end{array}$ & 55 & 55 & 16 \\
\hline $\begin{array}{l}\text { Quiz 5 (2h slot, } \\
\text { assignment due) }\end{array}$ & 39 & 68 & 50 \\
\hline Quiz 6 & 48 & 82 & 49 \\
\hline Average (\%) & 58 & & \\
\hline
\end{tabular}


Responses to student open-ended survey questions analysed by thematic analysis [34] revealed interesting findings. Surprisingly, a large number of respondents would like to receive additional readings, tutorials and/or workshops or longer interactive sessions. This is another confirmation of the popularity of the interactive sessions amongst the students. The second common topic was focused on lecture slides. Even though one might perceive the comments here as a negative, the intervention worked as planned - supporting the active engagement of students, their deeper learning and not memorization of the lecture content. The fact that "some slides didn't make sense until I came to the lecture and they were explained" was not disturbing as the slides were not designed to be self-explanatory and student attendance in lectures was expected. The quizzes were prepared in a way of testing student understanding and ability to find and apply the core principles, so the statement such as "it was almost impossible to find quiz answers from reading the slides before the lecture" was plausible. The fact that students found questions quite difficult or would like more questions/quizzes/discussions and problem-solving activities was also taken as a positive outcome of this study.

Comparisons of SECaTs data (based on students evaluations) with those from the previous year revealed an improved quality of the course. Students' perception of receiving helpful feedback on their learning in the course increased intensely (47 to $79 \%$ ). This was expected due to the implementation of this intervention (interactive lectures). The evaluations (especially "Encouraged student input") of the lecturer offering interactive lectures have also improved which is consistent with other findings.

Lecturers perceptions about the interactivity of the students in their lectures (without the intervention) scored 1 and 3 (out of 5) compared to 4 (lectures with intervention). Students were both asking and answering more questions during the lectures with the intervention. Students were contacting lecturer \#3 (with intervention) more often than those with lectures without intervention, however, this might be because lecturer \#3 was also the course coordinator. Lecturers \#1 and \#2 commented that students are mainly passive but responsive. Lecturer \#3 reported that students needed to be supported in discussion and participation.

The reflections during and after the interactive lectures confirmed that students participated in the class activities and discussions. Not only the student engagement and participation in the class increased but also student understanding of the topics discussed in the class (based on the questions students were asking). One of the problems identified was that students were not reading carefully the questions. The connection between lecture content and real-life made students very engaged, motivated and interested in the given topics.

To estimate $100 \%$ participation, students completed a "motivation statement". This was done to get students engaged and to make a connection to the real world. The number of student responses served as a positive control in this study. The result confirmed that all students present at the lecture participated in this activity, $71 \%$ was therefore used as $100 \%$ response of attending students. This activity was voluntary and was explained in the class and online but not in the Electronic Course Profile. For comparison, hurdle assignment 1 had participation $100 \%$ and assignment $298 \%$. It is also important to note, that quizzes 2-3 and 4-5 were in $2 \mathrm{~h}$ lecture slots (2 quizzes for those days) and therefore slightly lower participation in the second quiz in those slots was expected. Important information is that a major marked assignment was due on the date of quizzes 4-5. Perhaps, for this reason, the participation in quiz submission ( $82 \%$ of lecture attending students) was lower as this was only voluntary activity compared to the marked assignment.

The quizzes were voluntary activity before each class. Because the understanding of concepts was tested before the content was taught, the performance in quizzes cannot be used as a marker of improved student learning or topic understanding due to this intervention. One conclusion can be however drown here, and that is that students can learn almost $50 \%$ of the lecture content without attending the lecture if appropriate learning materials are provided. Therefore, the teacher can easily identify the problematic areas and spend more time in class to explain those more difficult principles in depth including practice examples.

The strength of this intervention is that it provides continuous feedback to students and lecturers on the students learning. A lecturer can recognize which content is poorly understood by students and can explain it further. Students can test their learning during the semester and feel less stressed during an examination. The strength of any evaluation is the use of multiple sources of data collection $[20,24]$. The data in this study were collected from qualitative and quantitative resources including evaluation of students and staff perceptions.

Limitation of the evaluation might be when students decide not to complete the survey. This could influence the outcome in case only highly engaged students and those who enjoyed the innovation responded. Due to ethical reasons, the survey cannot be compulsory and therefore students were only encouraged to participate. Another limitation was timing, pre- and post-test of the same cohort would prove an increased understanding of students engaging in interactive lectures compared to 
those who did not engage. The limitation could be the amount of understanding being tested via a quiz. A larger test would show more about student learning but that could also lead to an increased workload for lecturers.

\section{CONCLUSIONS}

Based on all perception and performance results from this intervention, it can be concluded that the inclusion of interactive lecture in traditional settings can improve student engagement and motivation to learn. The findings from this study confirm that undergraduate students can engage in a third year chemistry lecture. Moreover, students enjoyed and preferred this form of learning. Based on the student perception, the majority of students agreed with the positive effect of this study on their learning. Surprisingly, they would like to receive additional readings, tutorials and/or workshops. The highest average score from the student survey (4) was obtained for: "This teaching method is more efficient for my learning than traditional lecture without activities."

In general, course and teaching SECaTs evaluations for this course increased compared to the previous year with a significant $32 \%$ increase in receiving helpful feedback which is a challenging category. Impressive $100 \%$ agreement stands out on the teacher evaluation statement "Encouraged student input". The average participation in quizzes was $82 \%$ of lecture attending students with average marks around 50\%, which is remarkable considering those were being tested before the lectures. A future study could evaluate how students are learning/preparing for interactive lectures.

\section{ACKNOWLEDGMENTS}

This work was supported by the University of Queensland Research \& Teaching Award (ResTeach) for the Medicinal Chemistry Course (CHEM3008) and by the University of Queensland New Staff Start-Up Grant and both are gratefully acknowledged.

\section{REFERENCES}

[1] Sparkes, J.J. (1999). Learning-centered teaching. European Journal of Engineering Education, 24(2), 183188.

[2] DiCarlo, S.E. (2009). Too much content, not enough thinking, and too little fun! Advances in Physiology Education, 33, 257-264.

[3] Peralta, L., Callow, J., Freebody, K., Zhang, H. (2010). Planning for student engagement in lecture contexts. Synergy, 30, 41-47.

[4] Domizio, P. (2008). Giving a good lecture. Diagnostic Histopathology, 14(6), 284-288.
[5] Pundak, D., Rozner, S. (2008). Empowering engineering college staff to adopt active learning methods. Journal of Science Education and Technology, 17(2), 152-163.

[6] Baeten, M., Dochy, F., Struyven, K. (2008). Students' approaches to learning and assessment preferences in a portfolio-based learning environment. Instructional Science, 36, 359-374.

[7] Yew, L.T. (2005). Adoption of deep learning approaches by final year marketing students: A case study from Curtin University Sarawak. TL Forum. The Reflective Practitioner. Proceedings of the 14th Annual Teaching Learning Forum, 3-4 February 2005. Perth: Murdoch University.

[8] Biggs, J. (1999). Teaching for quality learning at university. SRHE and Open University Press, Buckingham, UK, 165-203.

[9] Young, M.S., Robinson, S., Alberts, P. (2009). Students pay attention! Combating the vigilance decrement to improve learning during lectures. Active Learning in Higher Education, 10(1), 41-55.

[10] Elliot, D. (2005). Early mornings and apprehension: Active learning in lectures. Journal of Hospitality Leisure Sport and Tourism, 4(1), 53-58.

[11] Charlton, B.G. (2006). Lectures are such an effective teaching method because they exploit evolved human psychology to improve learning. Medical Hypotheses, $67,1261-1265$.

[12] Broman, K. and Johnels, D. (2019). Flipping the class - University chemistry students' experiences from a new teaching and learning approach. Chemistry Teacher International, 1(1) https://doi.org/10.1515/cti2018-0004.

[13] Lindroth, T., Bergquist, M. (2010). Laptopers in an educational practice: Promoting the personal learning situation. Computers \& Education, 54, 311-320.

[14] Bhatti, I., Jones, K., Richardson, L., Foreman, D., Lund, J., Tierney, G. (2011). E-learning vs lecture: which is the best approach to surgical teaching? Colorectal Disease 13(4), 459-462.

[15] Rae, A., Samuels, P. (2011). Web-based personalised systems of instruction: An effective approach for diverse cohorts with virtual learning environments. Computers \& Education, 57, 2423-2431.

[16] Rose, J., Pennington, R., Behmke, D., Kerven, D., Lutz, R., Parades, J.E.B. (2019) Journal of Chemical Education, 96, 11, 2632-2637.

[17] McNamara, D.S. (2010). Strategies to read and learn: overcoming learning by consumption. Medical Education, 44, 340-346. 
[18] Biggs, J. (1996). Enhancing teaching through constructive alignment. Higher Education Research and Development, 32, 347-364.

[19] Quible, Z.K. (2002). Maximizing the effectiveness of electronic presentations. Business Communication Quarterly, 65(2), 82-85.

[20] Ramsden, P. (2003). The goals and structure of a course. Learning to Teach in Higher Education, $2^{\text {nd }}$ ed.; RoutledgeFalmer: New York, 209-232.

[21] Hounsell, D. (2009). Evaluating courses and teaching. In H. Fry, H.S. Ketteridge, \& S. Marshall (Eds.), A Handbook for Teaching and Learning in Higher Education: Enhancing Academic Practice ( $3^{\text {rd }}$ ed.) New York: Routledge, 198-211.

[22] Chen, H.T. (1996). Epilogue: Synthesizing formative/summative evaluation issues and beyond. Evaluation Practice, 17(2), 163-167.

[23] Bebell, D., O'Dwyer, L.M., Russell, M., Hoffmann, T. (2010). Concerns, considerations, and new ideas for data collection and research in educational technology studies. Journal of Research on Technology in Education, 43(1), 29-53.

[24] Guskey, T.R. (2007). Multiple sources of evidence: An analysis of stakeholders' perceptions of various indicators of student learning. Educational Measurement: Issues and Practice, 26(1), 19-27.

[25] Maydeu-Olivares, A. and Brown, A. (2011). Item response modeling of forced-choice questionnaires. Educational and Psychological Measurement, 71(3), 460-502.

[26] Flick, U. (2002). An Introduction to Qualitative Research ( $2^{\text {nd }}$ ed.) London:Sage.

[27] Cambell, E. (2003). The ethical teacher. Professional Learning, Maidenhead, England, Philadelphia: Open University Press, 1-56.

[28] Svinicki, M. (2002). Ethics in college teaching. In William J. McKeachie, McKeachie's teaching tips: Strategies, research, and theory for college and university teachers, Eleventh edition, Boston: Houghton Mifflin. Chapter 26, 306-318.

[29] Chabi, A.H., Kboubi, F., Ahmed, M.B. (2011). Thematic analysis and visualization of textual corpus. International Journal of Computer Science \& Engineering Survey 2(4), 15-31.

[30] Braun, V., Clarke, V. (2006). Using thematic analysis in psychology. Qualitative Research in Psychology, 3, 77-101.

[31] Jacobs, C. (2000). The evaluation of educational innovation. Evaluation, 6(3), 261-280.
[32] Harvey, J. (1998). Evaluation cookbook. Learning Technology Dissemination Initiative, Heriot-WattUniversity, Edinburgh.

[33] O'Cathain, A., Murphy, E., Nicholl, J. (2010). Three techniques for integrating data in mixed methods studies. British Medical Journal, 341(7783), 1147-1150.

[34] Karron, G.L. (2001). Making sense of student written comments. New Directions for Teaching and Learning, 87, 25-32. 